\title{
RESOLUÇÃO DO IBUPROFENO: UM PROJETO PARA DISCIPLINA DE QUÍMICA ORGÂNICA EXPERIMENTAL
}

\author{
Adriano L. Romero, Lúcia H. B. Baptistella, Fernando Coelho e Paulo M. Imamura* \\ Instituto de Química, Universidade Estadual de Campinas, CP 6154, 13084-970 Campinas - SP, Brasil
}

Recebido em 29/2/12; aceito em 3/4/12; publicado na web em 2/7/12

\begin{abstract}
RESOLUTION OF IBUPROFEN: A PROJECT FOR AN EXPERIMENTAL ORGANIC CHEMISTRY COURSE. A practical and didactic sequence of experiments was proposed to illustrate the stereochemistry concept, optically active compounds, resolution of racemates, and use of the NMR technique, including 2D-COSY for identification of organic compounds, on a laboratory course for undergraduate students. The sequence was: extractions of racemic ibuprofen and chiral naproxen from commercial tablets; syntheses of diastereoisomeric amides reacting chiral $(S)-(-)-\alpha$-methylbenzylamine with ( \pm )-ibuprofen; separation and determination of absolute configuration of amides by ${ }^{1} \mathrm{H}$ NMR spectroscopy and GC analysis, and hydrolysis of amides to obtain (+)- and (-)-ibuprofen.
\end{abstract}

Keywords: resolution of ibuprofen; stereochemistry; NMR Spectroscopy.

\section{INTRODUÇÃO}

Substâncias opticamente ativas com atividades farmacológicas sempre foram excelentes alvos para ilustrar a importância dos conhecimentos de estereoquímica em disciplinas de graduação. Desde o clássico caso da ação deletéria da $(S)$-talidomida ${ }^{1}$ até os mais recentes lançamentos de inibidores enzimáticos, ${ }^{2}$ os docentes podem encontrar nos livros texto ou na literatura em geral inúmeros exemplos para se aprofundar nos ensinamentos de um dos mais fascinantes tópicos da química. Nas disciplinas de química orgânica teórica em cursos de graduação, o assunto estereoquímica é, na maioria das vezes, muito bem tratado, inclusive com o uso, em classe, de modelos moleculares e de programas computacionais que facilitam o entendimento por parte dos alunos. ${ }^{3}$ Por outro lado, nas disciplinas experimentais, ainda se notam lacunas no tratamento de alguns dos itens abordados por esse assunto. Assim, enquanto inúmeros experimentos são propostos envolvendo extrações, sínteses ou análises de substâncias opticamente ativas, ${ }^{4-6}$ ainda faltam propostas de experimentos que tratem da resolução de enantiômeros. ${ }^{7-10}$ Neste contexto, uma das classes de fármacos quirais mais populares hoje em dia e que pode ser perfeitamente utilizada para tal fim é a dos anti-inflamatórios derivados do ácido propiônico, conhecidos como profenos, como o ibuprofeno (1), o naproxeno (2) e o cetoprofeno (3) (Figura 1). No caso do ibuprofeno (1), o enantiômero $(S)-(+)$ é o que apresenta maior afinidade pelas proteínas plasmáticas e, como consequência, melhor ação farmacológica. ${ }^{11}$ No entanto é conhecido, por testes biológicos realizados in vivo, que a enzima epimerase 2-arilpropionil-CoA é capaz de converter o $(R)$-(-)-ibuprofeno no seu enantiômero mais ativo $(S)-(+) .{ }^{12}$ Desta forma, devido ao alto custo envolvido na síntese de um enantiômero puro, os profenos são comercializados na forma racêmica, com exceção do naproxeno (2), disponível no mercado apenas como o isômero $(S)-(+)$, devido à ação hepatotóxica do enantiômero $(R)-(-){ }^{13}$

Com base nesse conjunto de informações e considerando o nosso interesse em sequências reacionais adequadas a uma disciplina de química orgânica experimental, ${ }^{14}$ foi elaborado um projeto para curso de graduação que ilustra conceitos de estereoquímica e resolução de racematos. Esse projeto envolveu extração do ( \pm )-ibuprofeno (1) e do (+)-naproxeno (2) a partir de fármacos comerciais; resolução

*e-mail: imam@iqm.unicamp.br

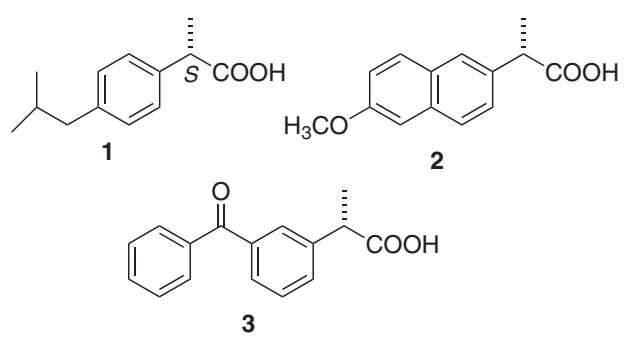

Figura 1. Estruturas dos compostos 1-3

do ( \pm -ibuprofeno (1) via síntese de amidas diastereoisoméricas utilizando $(S)$-(-)- $\alpha$-metilbenzilamina e hidrólise das ibuprofenamidas para obtenção do (+)- e do (-)-ibuprofeno. Todos os compostos foram devidamente caracterizados através das análises de dados físicos e espectroscópicos como p.f., rotação específica, IV, EM, CG, DSC e RMN ${ }^{1} \mathrm{H} \mathrm{e}^{13} \mathrm{C}$, incluindo experimento de 2D-COSY para as amidas quirais. A determinação da configuração absoluta das amidas diasteroisoméricas foi feita tanto por cromatografia gasosa quanto por análise de dados de $\mathrm{RMN}{ }^{1} \mathrm{H}$ utilizando $(S, S)$-ibuprofenamida como padrão. Embora o projeto tenha sido desenvolvido em 3 aulas de $8 \mathrm{~h}$ ( $2 \mathrm{~h}$ teoria $+6 \mathrm{~h}$ laboratório), pode ser ajustado de acordo com o enfoque e a disponibilidade de tempo para a disciplina em cada instituição.

\section{Algumas considerações sobre moléculas quirais e separação de enantiômeros}

Muitos dos compostos orgânicos presentes na natureza podem se apresentar nas duas formas enantioméricas, produzidos por diferentes organismos vivos. Isto se deve às enzimas que, por serem opticamente ativas, atuam em sistemas biológicos e produzem metabólitos secundários com especificidade estereoquímica. De modo geral, os organismos vivos produzem apenas um dos enantiômeros, enquanto que os métodos sintéticos convencionais (com exceção para reações assimétricas) levam a um racemato. Porém, são relatadas exceções na literatura onde as plantas produzem ambos enantiômeros e exemplos destas ocorrências estão se tornando cada vez mais frequentes. ${ }^{15}$

Como os enantiômeros possuem propriedades físicas idênticas, com exceção do desvio da luz no plano polarizado, a separação da mistura pelos métodos analíticos convencionais só é possível com a 
utilização de colunas cromatográficas quirais. ${ }^{16,17}$ Por outro lado, a resolução desta mistura de enantiômeros pode ser possível inicialmente por reação com um composto opticamente puro, quando os derivados diasteroisoméricos formados, com suas propriedades físicas diferentes, permitem a separação por métodos convencionais (como destilação fracionada, cristalização fracionada ou cromatografia), seguida pela reconversão dos diastereoisômeros em seu constituinte de interesse na forma enantiomérica pura.

\section{RESULTADOS E DISCUSSÃO}

Esse projeto teve início com a extração dos princípios ativos ibuprofeno (Motrin ${ }^{\circledR}$ ou Uniprofen ${ }^{\circledR}, 600 \mathrm{mg} / \mathrm{comprimido}$ ) e naproxeno (Naprosyn ${ }^{\circledR}$ ou Naprox, $250 \mathrm{mg} / \mathrm{comprimido}$ ) de seus respectivos comprimidos comerciais, utilizando acetato de etila. O ibuprofeno extraído, devidamente seco, teve suas propriedades físicas determinadas $\left\{\right.$ p.f. $=75-77{ }^{\circ} \mathrm{C}$ e $\left.[\alpha]_{\mathrm{D}}{ }^{20} 0^{\circ}(c 1,0 ; \mathrm{EtOH})\right\}$ e estas se mostraram concordantes com os valores descritos na literatura para a mistura racêmica. ${ }^{18} \mathrm{O}$ mesmo ocorreu com o naproxeno $\left\{\right.$ p.f. $=155-157^{\circ} \mathrm{C}$ e $\left.[\alpha]_{\mathrm{D}}{ }^{20}+66^{\circ}\left(c 1,0 ; \mathrm{CHCl}_{3}\right)\right\}$, quando comparado aos dados da literatura para o $(S)-(+)$-naproxeno. ${ }^{18} \mathrm{E}$ importante já incluir, nas explicações aos alunos, a importância da quiralidade na ação biológica de certas substâncias, ${ }^{19-21}$ e isto pode ser feito com exemplos clássicos como carvona (odor) ${ }^{4}$ limoneno (odor), ${ }^{22}$ glutamato de sódio (sabor) ${ }^{23}$ etc.

Em substâncias com o grupo funcional ácido carboxílico próximo ao centro estereogênico, como nas amostras em questão, uma maneira clássica de se fazer a resolução da mistura racêmica é através da preparação dos correspondentes sais ${ }^{4,6,8}$ ou outros derivados diasteroisoméricos dos ácidos utilizando um reagente quiral. ${ }^{10}$ Como já indicado, optou-se por preparar amidas diastereoisoméricas e isto foi feito pela reação entre o $( \pm)$-ibuprofeno e $(S)-(-)-\alpha$-metilbenzilamina (4) na presença de $N, N$ '-dicicloexilcarbodi-imida (DCC) ${ }^{24}$ (Esquema 1). O balão contendo solução do substrato e reagentes foi tampado com uma rolha e protegido da luz (deixado sob a bancada) até a próxima aula. Uma reação entre $(S)-(+)$-ibuprofeno (1) comercial, (S)-(-)- $\alpha$-metilbenzilamina (4) e DCC foi conduzida em paralelo, de modo a se ter uma ibuprofenamida padrão para os testes cromatográficos. Neste caso específico, é perfeitamente plausível organizar a classe para que uma única preparação da amostra-padrão seja feita para todo o laboratório.

Na segunda aula, a solução foi filtrada para remoção da dicicloexilureia formada e o filtrado foi analisado por CCD e por cromatografia

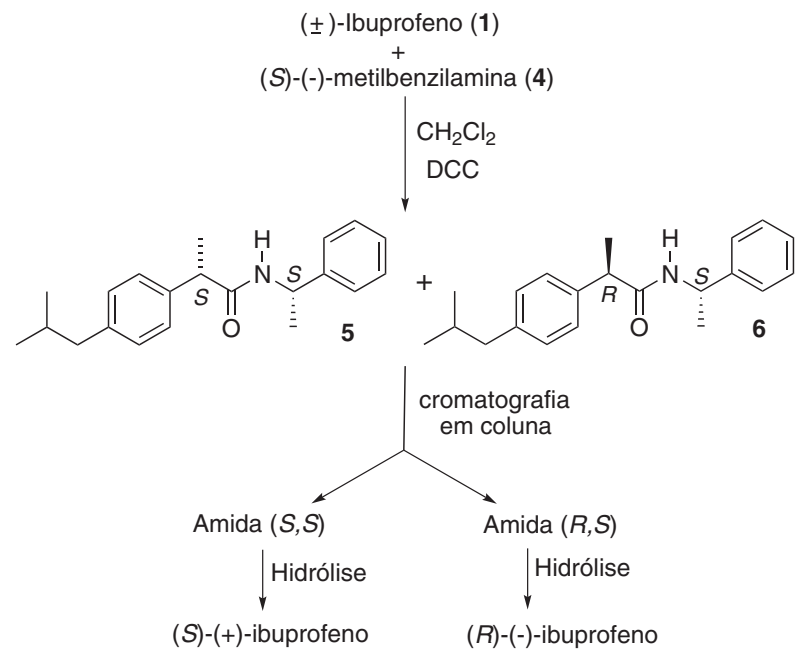

Esquema 1. Resolução de (土)-ibuprofeno (1) via formação de amidas diasteroisoméricas gasosa. Na CCD foram observadas duas manchas menos polares que o material de partida e de igual intensidade, correspondentes à formação das duas amidas diastereoisoméricas esperadas $\left(\mathrm{R}_{\mathrm{f}}=0,50\right.$ e 0,59; $n$-hexano:EtOAc, 8:2). O filtrado foi concentrado no rotaevaporador e as amidas diasteroisoméricas foram separadas por cromatografia em coluna de sílica gel ( $n$-hexano:EtOAc, 9:1). O desenvolvimento desta separação por cromatografia em coluna foi acompanhado por $\mathrm{CCD}$, as frações contendo as amidas diastereoisoméricas puras foram agrupadas e o solvente foi removido no rotaevaporador. Uma extração análoga foi feita para a $(S, S)$-ibuprofenamida (5). Cada uma das amidas diastereoisoméricas puras foi devidamente caracterizada através das análises de dados físicos e espectroscópicos.

A configuração absoluta das amidas diastereoisoméricas foi determinada, nesta etapa, por CCD, por CG e por análise dos dados de RMN ${ }^{1} \mathrm{H}$, sempre por comparação com os dados de $(S, S)$-ibuprofenamida (5) utilizada como padrão. A análise por cromatografia gasosa permitiu, através da coinjeção com o padrão, determinar a configuração absoluta da amida com menor tempo de retenção (tr 6,60 min) como sendo $(S, S)$ e da amida com maior tempo de retenção (tr 6,80 min) como sendo $(R, S)$ (Figura 2). Estes dados estão de acordo com os resultados observados por $\operatorname{Sen}^{7}$ e por Paik e colaboradores ${ }^{25}$ sendo que nesta última referência a comparação foi feita com os enantiômeros dos compostos em questão, já que os autores prepararam os respectivos diasteroisômeros utilizando $(R)-(+)-$ $\alpha$-metilbenzilamina. A análise e a atribuição dos sinais dos espectros de $\mathrm{RMN}$ de ${ }^{1} \mathrm{He}$ de ${ }^{13} \mathrm{C}$ das amidas diasteroisoméricas foram feitas por comparação com os dados do ibuprofeno e da $\alpha$-metilbenzilamina, sendo que a configuração absoluta de cada uma das amidas foi proposta por comparação de seus dados com os da $(S, S)$-ibuprofenamida (Tabela 1 - vide os espectros no material suplementar).

Embora os principais sinais de $\mathrm{RMN}$ de ${ }^{1} \mathrm{H}$ tenham sido atribuídos sem maiores dificuldades, a análise de espectro bidimensional (COSY 2D) permitiu atribuí-los de forma inequívoca. Assim, no espectro COSY 2D da (S,S)-ibuprofenamida (5) (Figura 3), observa-se que o sinal em $\delta 5,50$ (-CHN $\underline{H}-)$ está correlacionado ao sinal em $\delta 5,08(-\mathrm{C} \underline{H} \mathrm{NH}-)$ e que este, por sua vez, está correlacionado ao sinal em $\delta 1,34\left(\mathrm{C}_{3} \mathrm{CHNH}\right)$. O sinal em $\delta 3,50$ (-C $\left.\underline{\mathrm{HCO}}\right)$, que está correlacionado àquele em $\delta 1,51\left(\mathrm{C}_{3} \mathrm{CHCO}\right)$, encerra as principais atribuições da unidade ibuprofenamida. É importante salientar que esta análise do espectro de $\mathrm{RMN}{ }^{1} \mathrm{H}$ bidimensional de $\mathbf{5}$ serve não apenas para ilustrar aplicação desta técnica e sua importância, mas também fica evidente a atribuição equivocada descrita na literatura ${ }^{7}$ para a mesma amida.

Por fim, numa última aula, foi feita a reação de hidrólise das amidas para obtenção dos respectivos ibuprofenos. Os produtos isolados foram analisados por CG utilizando coluna quiral e caracterizados pelos dados de IV, RMN e DSC, além dos valores de ponto de fusão e rotação óptica.

Este projeto permitiu também ilustrar o uso da calorimetria exploratória diferencial (DSC - Differential Scan Calorimetry) que é uma técnica muito útil, mas pouco utilizada no meio acadêmico para estudo de pureza enantiomérica. Vale ressaltar, no entanto, que por ser um procedimento simples, rápido e de custo relativamente baixo, algumas indústrias farmacêuticas a utilizam sistematicamente como parâmetro para controle de qualidade de seus produtos. ${ }^{26}$ Com os alunos, foi realizada a análise da pureza enantiomérica de três amostras de ibuprofeno (Figura 4). A curva em verde representa a análise feita com o ibuprofeno extraído do fármaco, onde se observa apenas um pico de fusão em $78{ }^{\circ} \mathrm{C}$, de acordo com o descrito na literatura para o ácido em sua forma racêmica. ${ }^{18}$ Já as curvas em vermelho e azul representam os resultados obtidos para duas amostras de ibuprofeno quiral resolvidas via formação de amidas diasteroisoméricas (vermelho) e via formação de sais diastereoisoméricos (azul) (Esquema 2). ${ }^{27}$ 


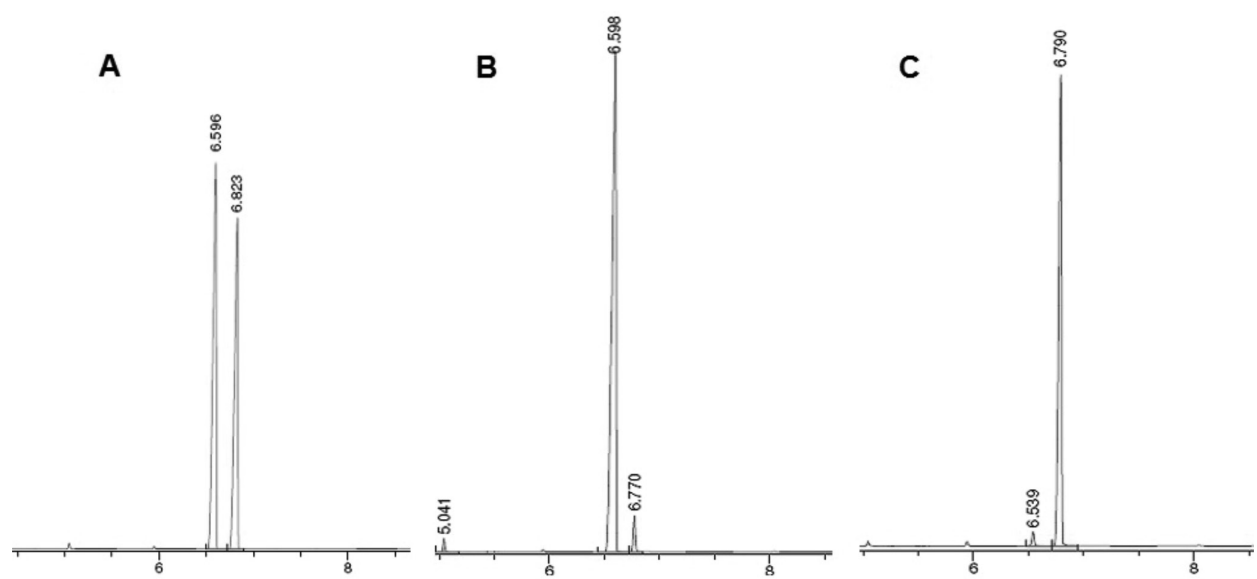

Figura 2. Cromatogramas $(C G)$ do filtrado da reação $(A=\mathbf{5}+\mathbf{6})$ e das amidas diasteroisoméricas puras $(B=5$ e $C=\mathbf{6})$

Tabela 1. Dados de RMN de ${ }^{1} \mathrm{H}(250 \mathrm{MHz})$ e de ${ }^{13} \mathrm{C}(62,5 \mathrm{MHz})$ dos compostos 1, 4-6 em $\mathrm{CDCl}_{3}$

\begin{tabular}{|c|c|c|c|c|c|c|c|c|}
\hline \multirow{2}{*}{ Posição } & \multicolumn{2}{|r|}{1} & \multicolumn{2}{|r|}{4} & \multicolumn{2}{|r|}{5} & \multicolumn{2}{|r|}{6} \\
\hline & $\delta_{\mathrm{C}}$ & $\delta_{\mathrm{H}}$ & $\delta_{\mathrm{C}}$ & $\delta_{\mathrm{H}}$ & $\delta_{\mathrm{C}}$ & $\delta_{\mathrm{H}}$ & $\delta_{\mathrm{C}}$ & $\delta_{\mathrm{H}}$ \\
\hline 1 & 181,0 & $10,38(s l)$ & & & 173,5 & - & 173,4 & - \\
\hline 2 & 44,98 & $3,72(q, J=7,2 \mathrm{~Hz})$ & & & 46,7 & $3,55(q, J=7,2 \mathrm{~Hz})$ & 46,7 & $3,50(q, J=7,3 \mathrm{~Hz})$ \\
\hline 3 & 140,8 & - & & & 140,6 & - & 140,6 & - \\
\hline 4 & 129,4 & $7,12(d, J=8,1 \mathrm{~Hz})$ & & & 129,6 & $7,04-7,24(m)$ & 129,7 & $7,10-7,30(\mathrm{~m})$ \\
\hline 5 & 127,3 & $7,24(d, J=8,1 \mathrm{~Hz})$ & & & 127,2 & $7,04-7,24(\mathrm{~m})$ & 127,3 & $7,10-7,30(\mathrm{~m})$ \\
\hline 6 & 137,0 & - & & & 138,6 & - & 138,5 & - \\
\hline 7 & 45,02 & $2,47(d, J=7,2 \mathrm{~Hz})$ & & & 45,0 & $2,45(d, J=6,7 \mathrm{~Hz})$ & 45,0 & $2,46(d, J=6,7 \mathrm{~Hz})$ \\
\hline 8 & 30,1 & $1,84(n, J=6,8 \mathrm{~Hz})$ & & & 30,1 & $1,85(n, J=6,7 \mathrm{~Hz})$ & 30,1 & $1,86(n, J=6,7 \mathrm{~Hz})$ \\
\hline 9 & 22,4 & $0,89(d, J=6,6 \mathrm{~Hz})$ & & & 22,3 & $0,89(d, J=6,6 \mathrm{~Hz})$ & 22,3 & $0,90(d, J=6,6 \mathrm{~Hz})$ \\
\hline 10 & 22,4 & $0,89(d, J=6,6 \mathrm{~Hz})$ & & & 22,3 & $0,89(d, J=6,6 \mathrm{~Hz})$ & 22,3 & $0,90(d, J=6,6 \mathrm{~Hz})$ \\
\hline 11 & 18,1 & $1,52(d, J=7,2 \mathrm{~Hz})$ & & & 18,4 & $1,49(d, J=7,2 \mathrm{~Hz})$ & 18,4 & $1,51(d, J=7,3 \mathrm{~Hz})$ \\
\hline $1^{\prime}$ & & & 51,2 & $4,10(q, J=5,0 \mathrm{~Hz})$ & 48,6 & $5,06(q, J=7,4 \mathrm{~Hz})$ & 48,6 & $5,08(q, J=7,3 \mathrm{~Hz})$ \\
\hline $2^{\prime}$ & & & 25,6 & $1,38(d, J=5,0 \mathrm{~Hz})$ & 21,9 & $1,37(d, J=7,0 \mathrm{~Hz})$ & 21,6 & $1,34(d, J=7,0 \mathrm{~Hz})$ \\
\hline $3^{\prime}$ & & & 147,7 & - & 143,2 & - & 143,2 & - \\
\hline 4 ' & & & 125,6 & $7,20-7,26(m)$ & 125,9 & 7,04-7,24 (m) & 126,0 & $7,10-7,30(\mathrm{~m})$ \\
\hline $5^{\prime}$ & & & 128,4 & 7,29-7,36 (m) & 128,5 & 7,04-7,24 (m) & 128,5 & $7,10-7,30(\mathrm{~m})$ \\
\hline $6^{\prime}$ & & & 126,7 & 7,29-7,36 (m) & 127,0 & $7,04-7,24(\mathrm{~m})$ & 127,1 & $7,10-7.30(\mathrm{~m})$ \\
\hline $\mathrm{N}-\mathrm{H}$ & & & & $1,60(s l)$ & & $5,62(d, J=7,4 \mathrm{~Hz})$ & & $5,50(d, J=7,3 \mathrm{~Hz})$ \\
\hline
\end{tabular}

Para o ibuprofeno proveniente da amida há apenas um pico de fusão em $56^{\circ} \mathrm{C}$, valor este próximo ao descrito na literatura para a forma enantiomericamente pura do (S)-ibuprofeno. ${ }^{28}$ Já para o ibuprofeno proveniente do sal diasteroisomérico, observam-se dois picos de fusão (em $56^{\circ} \mathrm{C}$ e em $77^{\circ} \mathrm{C}$ ) o que mostra de forma qualitativa que a resolução não foi total. $\mathrm{O}$ excesso enantiomérico desta amostra não foi calculado, mas pode ser determinado através da relação das áreas integradas de cada pico de fusão. Os dados apresentados aqui estão de acordo com os de um estudo feito por Mitchell e colaboradores para o ibuprofeno. ${ }^{29}$

\section{CONCLUSÃO}

Esta proposta para disciplina experimental de química orgânica engloba vários aspectos importantes para um aluno de graduação, podendo ser citados: i) a parte sintética, com a preparação de amidas diretamente de ácidos carboxílicos e suas respectivas hidrólises, o que permite explorar a estabilidade relativa de derivados de ácidos carboxílicos; ii) o tratamento bastante amplo de tópicos de estereoquímica, com especial ênfase à separação de enantiômeros, utilizando fármacos conhecidos de todos como substratos; iii) a possibilidade de usar dados físicos e espectroscópicos para evidenciar as diferenças de propriedades entre pares de enantiômeros e de diastereoisômeros. $\mathrm{O}$ projeto ilustra, adicionalmente, a aplicabilidade da calorimetria exploratória diferencial (DSC), técnica ainda pouco usada em laboratórios de ensino.

\section{PARTE EXPERIMENTAL}

\section{Métodos gerais}

Os espectros de RMN foram obtidos em um espectrômetro Bruker Avance 250, operando a $250 \mathrm{MHz}$ para ${ }^{1} \mathrm{H}$ e a $62,5 \mathrm{MHz}$ para ${ }^{13} \mathrm{C}$, sendo utilizado o sinal do solvente como referencial interno e as amostras dissolvidas em $\mathrm{CDCl}_{3}$. As rotações ópticas foram medidas em um polarímetro Perkin-Elmer modelo 341. Os pontos de fusão, 


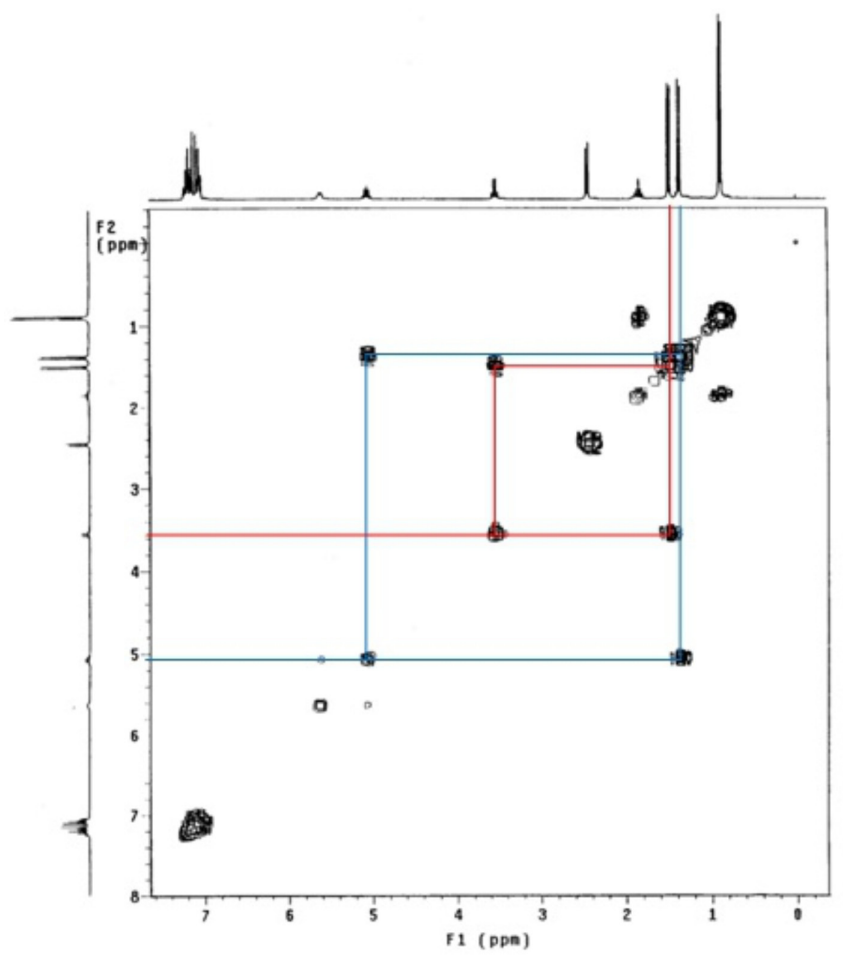

Figura 3. Mapa de contorno $2 \mathrm{D}$ de correlações ${ }^{1} \mathrm{H},{ }^{1} \mathrm{H}(\mathrm{COSY})(250 \mathrm{MHz})$ da $(S, S)$-ibuprofenamida (5) em $\mathrm{CDCl}_{3}$

$$
\text { ( } \pm \text { )-lbuprofeno (1) }
$$

(S)-(-)-metilbenzilamina (4)

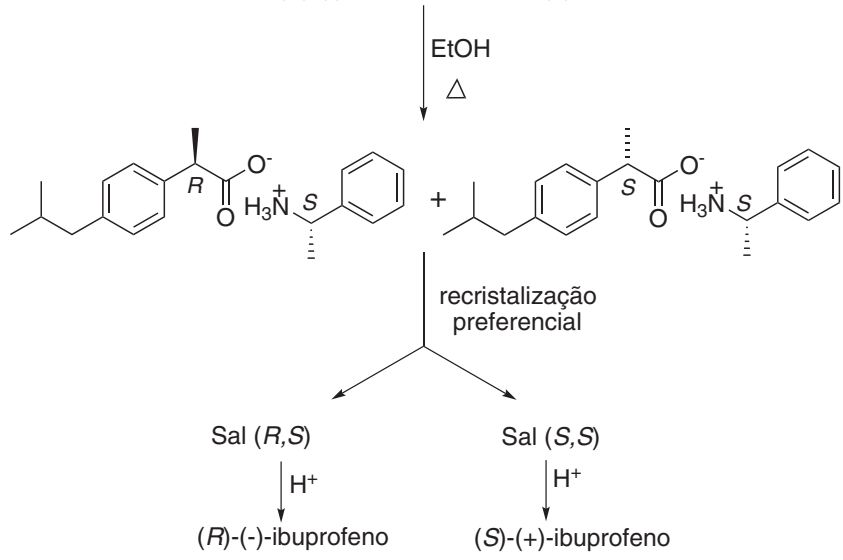

Esquema 2. Resolução de (士)-ibuprofeno (1) via formação de sais diasteroisoméricos

não corrigidos, foram determinados utilizando aparelho Mettler FP-52. Os espectros de absorção na região do infravermelho foram obtidos em espectrômetro Perkin-Elmer 298, em partilhas de $\mathrm{KBr}$.

\section{Cromatografia gasosa}

Os cromatogramas foram obtidos em um cromatógrafo a gás Hewlett Packard 5890B Series II, usando uma coluna HP-5 (30 m x $0,32 \mathrm{~mm} \times 0,25 \mathrm{~mm})$, hélio como gás de arraste (100 pKA) e divisor de fluxo 1:50. Programação de temperatura do forno: $80-160{ }^{\circ} \mathrm{C}$ com taxa de $4{ }^{\circ} \mathrm{C} / \mathrm{min}$. As temperaturas do injetor e detector foram mantidas em 260 e $290{ }^{\circ} \mathrm{C}$, respectivamente. Foram injetadas $0,2 \mu \mathrm{L}$ das amostras ( $\mathrm{c} \approx 1 \mathrm{mg} / \mathrm{mL}$ em AcOEt). As composições percentuais foram obtidas a partir de medidas de integração eletrônica utilizando detector de ionização em chama (FID).

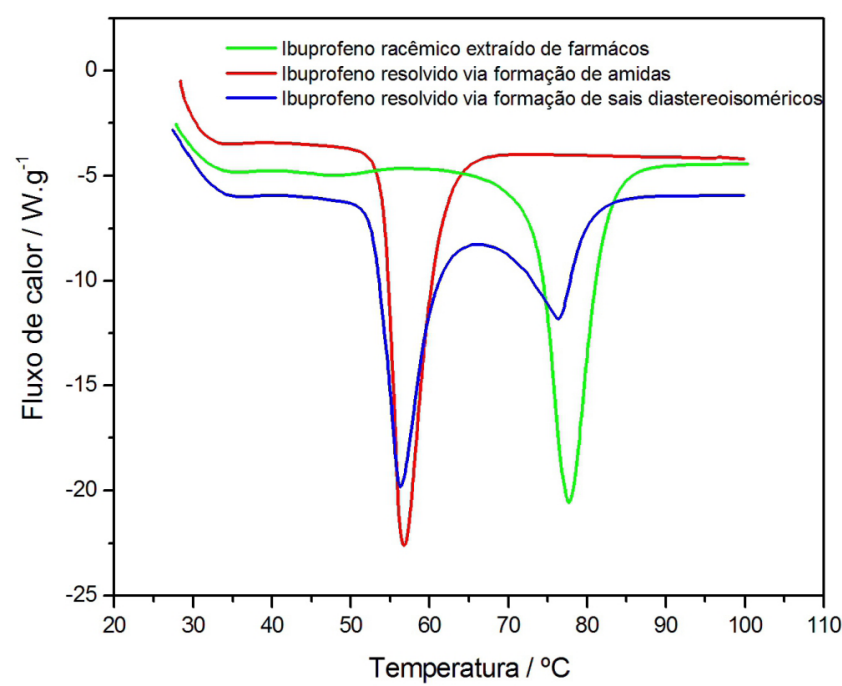

Figura 4. Termograma diferencial (DSC) do ibuprofeno (1)

\section{Calorimetria exploratória diferencial (DSC)}

Os termogramas de DSC foram obtidos num equipamento da TA Instruments, modelo 2910, operando sob atmosfera de argônio. As análises foram conduzidas em amostras secas (5-7 mg), utilizando varredura de $25-100{ }^{\circ} \mathrm{C} \mathrm{a} 10^{\circ} \mathrm{C} / \mathrm{min}$. Os valores de temperatura não foram corrigidos.

\section{Extração de profenos a partir de fármacos comerciais}

Os medicamentos comerciais utilizados nesse projeto foram Motrin ${ }^{\circledR}$ e Uniprofen ${ }^{\circledR}$ para ibuprofeno (600 mg/comprimido) e Naprosyn $^{\circledR}$ e Naprox $^{\circledR}$ para naproxeno (250 mg/comprimido). Um comprimido do medicamento comercial contendo profeno (ibuprofeno ou naproxeno) foi triturado em um almofariz e, em seguida, transferido para um Erlenmeyer de $125 \mathrm{~mL}$ contendo $40 \mathrm{~mL}$ de acetato de etila. Após agitação vigorosa por $10 \mathrm{~min}$, a solução foi filtrada, o resíduo lavado com $10 \mathrm{~mL}$ de acetato de etila e o solvente foi removido no rotaevaporador. O rendimento da extração foi, em todos os casos, superior a $90 \%$ do valor informado pelo fabricante.

\section{(土)-Ibuprofeno $(\boldsymbol{1})$}

P.f.: $75-77^{\circ} \mathrm{C}$; $[\alpha]_{\mathrm{D}}^{20} 0^{\circ}$ (c 1,0 ; EtOH) (lit. ${ }^{18}$ p.f. $\left.75-77{ }^{\circ} \mathrm{C}\right)$; IV $(\mathrm{KBr}) \vee\left(\mathrm{cm}^{-1}\right): 3904,2952,1718,1508,1419,1327,1228,1178$, 1074, 937, 864. RMN de ${ }^{1} \mathrm{H}$ e de ${ }^{13} \mathrm{C}$ (Tabela 1).

\section{(S)-(+)-Naproxeno $(2)$}

P.f.: $155-157^{\circ} \mathrm{C},[\alpha]_{\mathrm{D}}^{20}+66^{\circ}\left(\mathrm{c} 1,0 ; \mathrm{CHCl}_{3}\right)\left(\right.$ lit. ${ }^{18}$ p.f. $152-154^{\circ} \mathrm{C}$, $\left.[\alpha]_{\mathrm{D}}^{20}+66^{\circ}, \mathrm{CHCl}_{3}\right) ; \mathrm{IV}(\mathrm{KBr}) \vee\left(\mathrm{cm}^{-1}\right): 3209,2947,2578,1726$, $1464,1388,1269,1163,862$. RMN de ${ }^{1} \mathrm{H}\left(250 \mathrm{MHz}, \mathrm{CDCl}_{3}\right)-\delta_{\mathrm{H}}$ (multiplicidade, $J$ em Hz): 1,57 (d, $J=7,2 \mathrm{~Hz}, 3 \mathrm{H}, \mathrm{H}-3$ ); 3,88 (s, $3 \mathrm{H}, \mathrm{H}-14) ; 7,09$ (t, $J=2,3 \mathrm{~Hz}, 1 \mathrm{H}, \mathrm{H}-10) ; 7,13$ (dd, $J=8,5$ e 2,3 Hz, $1 \mathrm{H}, \mathrm{H}-8) ; 7,39$ (dd, $J=8,5$ e 2,0 Hz, 1H, H-13); 7,62-7,72 (m, 3H, $\mathrm{H}-5, \mathrm{H}-7, \mathrm{H}-12)$. RMN de ${ }^{13} \mathrm{C}\left(62,5 \mathrm{MHz}, \mathrm{CDCl}_{3}\right)-\delta_{\mathrm{C}}: 18,1(\mathrm{C}-3)$; 45,3 (C-2); 55,3 (C-14); 105,55 (C-10); 119,0 (C-8); 126,12 e 126,16 (C-5 e C-13); 127,2 (C-12); 128,9 (C-6); 129,3 (C-7); 133,8 (C-11); 134,8 (C-4); 157,7 (C-9); 181,0 (C-1).

\section{Preparação da (S,S)-ibuprofenamida (5) (opcional)}

(S)-(+)-Ibuprofen (206,3 mg, 1,0 mmol) e $N, N^{\prime}$-dicicloexilcarbodi-imida (DCC) $(258,0 \mathrm{mg}, 1,25 \mathrm{mmol})$ foram adicionadas a uma solução de $(S)$ - $\alpha$-metilbenzilamina $(0,15 \mathrm{~mL}, 1,1 \mathrm{mmol}) \mathrm{em}$ 
diclorometano ( $10 \mathrm{~mL})$. A mistura foi agitada por $5 \mathrm{~h} \mathrm{e}$, em seguida, a dicicloexilureia formada foi filtrada e o solvente removido no rotaevaporador. O produto bruto foi purificado por cromatografia em coluna de sílica gel ( $n$-hexano:AcOEt, 7:3) para fornecer 296,0 mg (96\% de rendimento) da $(S, S)$-ibuprofenamida (5) como um sólido incolor, p.f.: 107-109 ${ }^{\circ} \mathrm{C},\left[[\alpha]_{\mathrm{D}}^{20}-25,5^{\circ}\right.$ (c 2,0, $\mathrm{CHCl}_{3}$ ), Rf 0,50 (hexano:AcOEt, 7:3), IV (KBr) $\vee\left(\mathrm{cm}^{-1}\right): 3289,2954,2924,1642,1541,699 . \mathrm{RMN}$ de ${ }^{1} \mathrm{H}$ e de ${ }^{13} \mathrm{C}$ (Tabela 1). Anal. calc. para $\mathrm{C}_{21} \mathrm{H}_{27} \mathrm{NO}$ : C, 81,51; $\mathrm{H}$ 8,79; N, 4,53. Encontrado: C, 81,39, H, 9,00, N, 4,70.

\section{Preparação das ibuprofenamidas diastereoisoméricas}

(土)-Ibuprofeno (1) (1,0 g, 4,85 mmol) e DCC (1,2 g, 5,82 mmol) foram adicionados a uma solução de $(S)-(-)$ - $\alpha$-metilbenzilamina $(0,75$ $\mathrm{mL}, 5,87 \mathrm{mmol})$ em diclorometano $(30 \mathrm{~mL})$. O balão foi tampado e guardado sob a bancada até a próxima aula. Após o período indicado, a solução foi filtrada para remoção da dicicloexilureia e o solvente removido no rotaevaporador, fornecendo $1,492 \mathrm{~g}$ de produto bruto. A análise do produto de reação por CCD [hexano:acetato de etila (7:3)] mostrou duas manchas após revelado na lâmpada UV, em seguida, com uma solução de $p$-anisaldeído ( $p$-anisaldeído/ $\mathrm{H}_{2} \mathrm{SO}_{4} / \mathrm{HOAc}$ - 0,5:1,0:50 $\mathrm{mL}$ e, em seguida, aquecida numa placa de aquecimento elétrico).

A purificação do produto (cerca de $1,0 \mathrm{~g}$ ) foi feita em coluna de cromatografia em coluna de sílica gel (20 g) e eluída com hexano:acetato de etila (8:2). Foram coletadas cerca de 30 frações de aproximadamente $10 \mathrm{~mL} /$ fração e, em seguida, cada fração foi analisada por CCD. As frações foram agrupadas de acordo com o perfil cromatográfico onde foram obtidos $0,544 \mathrm{~g}$ (36\% de rendimento) da amida $(R, S)$-ibuprofenamida [Rf 0,59 em hexano:AcOEt 7:3], $0,475 \mathrm{~g}$ (32\% de rendimento) da (S,S)-ibuprofenamida [Rf 0,50 em hexano:AcOEt 7:3] e uma fração contendo mistura das duas amidas $(0,188 \mathrm{~g})$.

\section{(S,S)-ibuprofenamida (5)}

Os dados físicos e espectroscópicos se mostraram idênticos ao obtido anteriormente.

\section{$(R, S)$-ibuprofenamida $(\mathbf{6})$}

P.f.: $94-96{ }^{\circ} \mathrm{C},[\alpha]_{\mathrm{D}}^{20}+17,0^{\circ}\left(\mathrm{c} 2,0 ; \mathrm{CHCl}_{3}\right) ; \mathrm{R}_{\mathrm{f}}=0,59 ; n-$ -hexano:EtOAc, 8:2); IV (KBr) v ( $\left.\mathrm{cm}^{-1}\right)$ : 3317, 2951, 1640, 1534, 697. RMN de ${ }^{1} \mathrm{H}$ e de ${ }^{13} \mathrm{C}$ (Tabela 1 ).

\section{Hidrólise da (S,S)-ibuprofenamida (5)}

Em um balão de $10 \mathrm{~mL}$ contendo $465 \mathrm{mg}(1,5 \mathrm{mmol}) \mathrm{da}(S, S)$ ibuprofenamida (5) foram adicionados 5,0 mL de uma solução $\mathrm{HCl}: \mathrm{H}_{2} \mathrm{O}$ (1:1). A solução foi aquecida em uma manta de aquecimento até a ebulição e mantida sob refluxo por $50 \mathrm{~min}$. A solução foi resfriada e, em seguida, adicionou-se solução de $\mathrm{NaOH} 20 \%$ até $\mathrm{pH} 10$ e extraiu-se com diclorometano $(3 \times 10 \mathrm{~mL})$ para remover os compostos nitrogenados. Na sequência, a fase aquosa foi acidificada até $\mathrm{pH} 2$ com uma solução de $\mathrm{HCl} 6 \mathrm{~mol} \mathrm{~L}^{-1}$ e extraiu-se com diclorometano ( $3 \times 10 \mathrm{~mL})$. A fase orgânica reunida foi seca com $\mathrm{Na}_{2} \mathrm{SO}_{4}$ anidro, filtrada e o solvente removido no rotaevaporador. A recuperação do ibuprofeno nesta etapa foi de 262,1 mg (90\% de rendimento).

\section{(S)-Ibuprofeno $(\mathbf{1})$}

P.f.: $50-51^{\circ} \mathrm{C},[\alpha]_{\mathrm{D}}^{20}+58.0^{\circ}(c 2,0 ; \mathrm{EtOH})\left\{\right.$ lit. $^{16}$ : p.f. $51,1^{\circ} \mathrm{C}$; lit..$^{28}$ : p.f. $\left.51-53^{\circ} \mathrm{C},[\alpha]_{\mathrm{D}}^{20}+59^{\circ}(\mathrm{c} 2,0 ; \mathrm{EtOH})\right\}$. RMN de ${ }^{1} \mathrm{H}$ e de ${ }^{13} \mathrm{C}$ idênticos aos obtidos do ibuprofeno (1) extraído de fármaco (Tabela 1).

\section{Hidrólise da (R,S)-ibuprofenamida (6)}

A hidrólise da $(R, S)$-ibuprofenamida (6) foi realizada utilizando o mesmo procedimento descrito para a $(S, S)$-ibuprofenamida (5).

\section{(R)-Ibuprofeno $(\boldsymbol{1})$}

P.f.: $50-51^{\circ} \mathrm{C},[\alpha]_{\mathrm{D}}^{20}-57.5^{\circ}$ (c 2,0; EtOH). RMN de ${ }^{1} \mathrm{H}$ e de ${ }^{13} \mathrm{C}$ idênticos aos obtidos para o ibuprofeno (1) extraído de fármaco (Tabela 1).

\section{CONSIDERAÇÕES FINAIS}

As determinações estruturais dos compostos isolados e sintetizados permitiram aos estudantes aplicarem os conhecimentos adquiridos durante o curso em disciplinas de espectroscopia. Além disso, a resolução de enantiômeros via formação de diastereoisômeros é uma metodologia clássica e é um bom exemplo para estudos de mecanismo de reações orgânicas. Embora o projeto permita flexibilização e possibilite utilização de outros profenos, assim como de outras bases enantiomericamente puras, o resultado obtido com o ibuprofeno foi melhor do que com o experimento realizado com o naproxeno.

\section{MATERIAL SUPLEMENTAR}

O método para extração de naproxeno sódico e os espectros de RMN de ${ }^{1} \mathrm{H},{ }^{13} \mathrm{C}$ e COSY dos compostos extraídos e sintetizados estão disponíveis em http://quimicanova.sbq.org.br, em arquivo pdf, com acesso livre.

\section{AGRADECIMENTOS}

Aos alunos dos cursos de química e farmácia da UNICAMP que executaram este projeto durante a disciplina química orgânica experimental ao longo de vários anos.

\section{REFERENCIAS E NOTAS}

1. Stephens, T. D.; Bunde, C. J. W.; Fillmore, B. J.; Biochem. Pharmacol. 2000, 59, 1489

2. Krogsgaard-Larsen, P.; Madsen, U.; Stromgaard, K., eds.; A Textbook of Drug Design and Discovery, CRC Press: Boca Raton, 2009, $4^{\text {th }}$ ed.; Silverman, R.B.; The Organic Chemistry of Drug Design and Drug Action, Elsevier Academic Press: San Diego, 2004, $2^{\text {nd }}$ ed.; p. 227-307.

3. Por exemplo, Spartan Model: an electronic model kit, Wavefunction, Inc., http://www.wavefun.com/products/windows/SpartanModel/ win_model.html, acessada em Fevereiro 2012; ChemSteck e ACD Software Suitete, http://www.acdlabs.com acessada em Fevereiro 2012; ChemDraw Ultra 12.0 Suite, Perkin Elmer, http://www.cambridgesoft. com acessada em Fevereiro 2012.

4. Pavia, D. L.; Lampman, G. M.; Kriz, G. S.; Engel, R. G.; Química Orgânica Experimental, Técnicas de escala pequena, Bookman Co. Ed.: Porto Alegre, $2^{\mathrm{a}}$ ed.; 2005.

5. Wyatt, J. K.; Bolton, C. L.; Correia; M. C.; Watson, C. M.; Chem. Educ. 2006, 11, 93 .

6. Allen, D. A.; Tomaso, A. E.; Priest, O. P.; Hindson, D. F.; Hurlburt, J. L.; J. Chem. Educ. 2008, 85, 698.

7. Sen, S. E.; Anliker, K. S.; J. Chem. Educ. 1996, 73, 569.

8. McCullagh, J. V.; J. Chem. Educ. 2008, 85, 941.

9. Walsh, T. D.; Koontz, C. S.; Baar, M. R.; J. Chem. Educ. 1997, 74, 585; Monteiro, C. M.; Afonso, C. A. M.; J. Chem. Educ. 2010, 87, 423.

10. Baar, M. R.; Cerrone-Szakal, A. L.; J. Chem. Educ. 2005, 82, 1040.

11. Barreiro, E. J.; Fraga, C. A. M.; Química Medicinal. As bases moleculares da ação dos fármacos, Ed. Artmed: Porto Alegre, 2001, p. 159.

12. Reichel. C.; Brugger, R.; Bang, H.; Geisslinger, G.; Brune, K.; Mol. Pharmacol. 1997, 51, 576. 
13. Caron, G.; Tseng, G. W. M.; Kazlauskas, R. J.; Tetrahedron Asymmetry 1994, 5,83 .

14. Imamura, P. M.; Baptistella, L. H. B.; Quim. Nova 2000, 23, 270; Baptistella, L. H. B.; Giacomini, R. A.; Imamura, P. M.; Quim. Nova 2003, 26, 284; Baptistella, L. H. B.; Imamura, P. M.; de Melo, L.V.; Castelo, C.; Quim. Nova 2009, 32, 1069.

15. König W. A.; Chirality 1998, 10, 499; Romero, A. L.; Baptistella, L. H. B.; Imamura, P. M.; J. Braz. Chem. Soc. 2009, 20, 1036.

16. Ebbers, E. J.; Ariaans, G. J. A.; Bruggink, A.; Zwanenburg, B.; Tetrahedron Asymmetry 1999, 10, 3701.

17. Vadinská, M.; Basáková, Z.; Tesarová, E.; Coufal, P.; Planeta, J.; Chromatographia Supl. 2008, 67, S33.

18. The Merck Index, $12^{\text {th }}$ ed.; Merck Research Laboratory Publish: New Jersey, 1996.

19. Harrison, I. T.; Lewis, B.; Nelson, P.; Rooks, W.; Roszkowski, A.; Tomolonis, A.; Fried, J. H.; J. Med. Chem. 1970, 13, 203.

20. Manimaran T.; Stahly, G. P.; Tetrahedron Asymmetry 1993, 4, 1949.

21. Barreiro, E. J.; Ferreira, V. F.; Costa, P. R. R.; Quim. Nova 1997, 20, 647.

22. Barbosa, L. C. A.; Introdução à Química Orgânica, Ed. UFV e Pearson Prentice Hall: Viçosa, 2004.
23. Bettelheim, F. A.; Brown, W. H.; March, J.; Introduction to General, Organic \& Biochemistry, Harcourt College Publ.: Orlando, $6^{\text {th }}$ ed.; 2001, p. 642; Hettinger, T. P.; Frank, M. E.; Myers, W. E.; Chemical Senses 1996, 21,341 .

24. Trost, B. M.; Belletire, J. L.; Godleski, S.; McDougal, P. G.; Balkovec, J. M.; Baldwin, J. J.; Christy, M. E.; Ponticello, G. S.; Varga, S. L.; Springer, J. P.; J. Org. Chem. 1986, 51, 2370.

25. Paik, M.-J.; Lee, Y.; Goto, J.; Kim, K.-R.; J. Chromatogr., B: Anal. Technol. Biomed. Life Sci. 2004, 803, 257.

26. Holler, F. J.; Skoog, D. A.; Crouch, S. R.; Princípios de Análise Instrumental, Ed. Bookman: São Paulo, 6a ed., 2009, cap. 31.

27. A preparação dos sais diastereoisoméricos citados e a posterior separação dos ibuprofenos enantioméricos, mostrada no Esquema 2, foi feita pelo monitor da disciplina, de acordo com a ref. 8.

28. Manual de Produtos Químicos Finos da Aldrich - Desenvolvendo Ciência, Sigma-Aldrich Co.; São Paulo, 2007-2008, p. 1463.

29. Dwiverdi, S. K.; Sattari, S.; Jamali, F.; Mitchell, A. G.; Int. J. Pharm. 1992, 87, 95. 


\section{RESOLUÇÃO DO IBUPROFENO: UM PROJETO PARA DISCIPLINA DE QUÍMICA ORGÂNICA EXPERIMENTAL}

Adriano L. Romero, Lúcia H. B. Baptistella, Fernando Coelho e Paulo M. Imamura*

Instituto de Química, Universidade Estadual de Campinas, CP 6154, 13084-970 Campinas - SP, Brasil

1. Extração do sal sódico do naproxeno: cinco comprimidos de "Flanax" foram triturados em um gral e o material foi transferido para um Erlenmeyer de $125 \mathrm{~mL}$. Em seguida, foram adicionados $30 \mathrm{~mL}$ de metanol e deixado sob agitação magnética durante cerca de 15 min. Após este período, a solução foi filtrada num papel de filtro pregueado para um balão e, em seguida, o solvente foi removido no rotaevaporador.

2. Obtenção do naproxeno: em um Erlenmeyer de $125 \mathrm{~mL}$ foram adicionados $500 \mathrm{mg}$ de sal sódico de naproxeno, $10 \mathrm{~mL}$ de água destilada para dissolução e, em seguida, foi adicionada, gota a gota, uma solução de ácido clorídrico $3 \mathrm{~mol} / \mathrm{L}^{-1}$ até $\mathrm{pH}$ próximo de 2 . A solução foi extraída com diclorometano ( $3 \times 25 \mathrm{~mL})$, as fases orgânicas ajuntadas e lavadas com $10 \mathrm{~mL}$ de água desti- lada. Após tratamento com sulfato de sódio anidro por 15 min, a solução foi filtrada, o resíduo lavado com diclorometano e o solvente foi removido no rotaevaporador.

3. Resolução do ibuprofeno via do sal de amina quiral: a resolução do (+/-)-ibuprofeno através da formação de sal com $(S)$ - $\alpha$-metilbenzilamina foi feita segundo o procedimento descrito na literatura. ${ }^{1}$

\section{REFERENCIA}

1. McCullagh, J. V.; J. Chem. Educ. 2008, 85, 941.

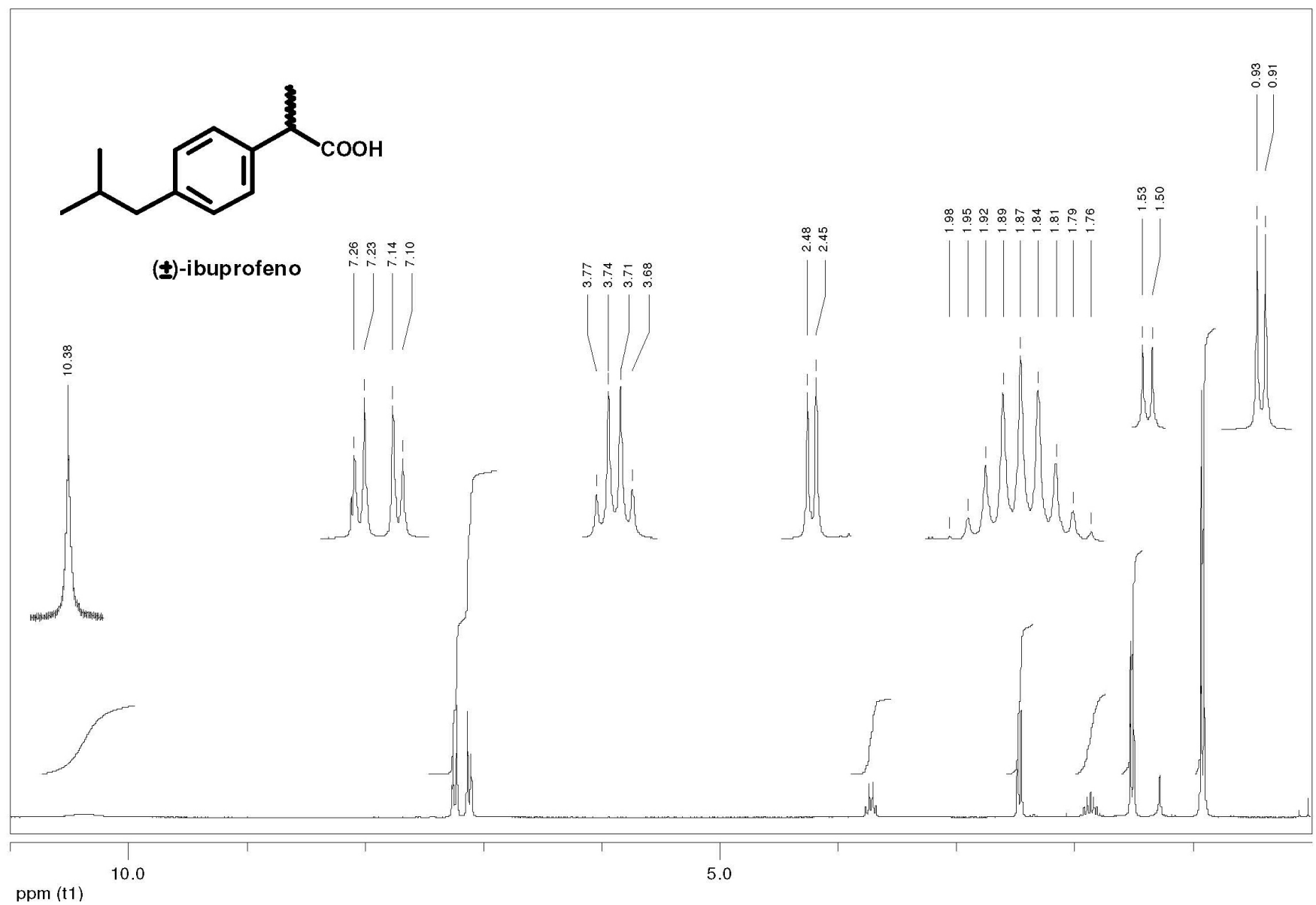

Figura 1S. Espectro de $\mathrm{RMN}$ de ${ }^{1} \mathrm{H}\left(250 \mathrm{MHz}, \mathrm{CDCl}_{3}\right)$ do ibuprofeno (1) 


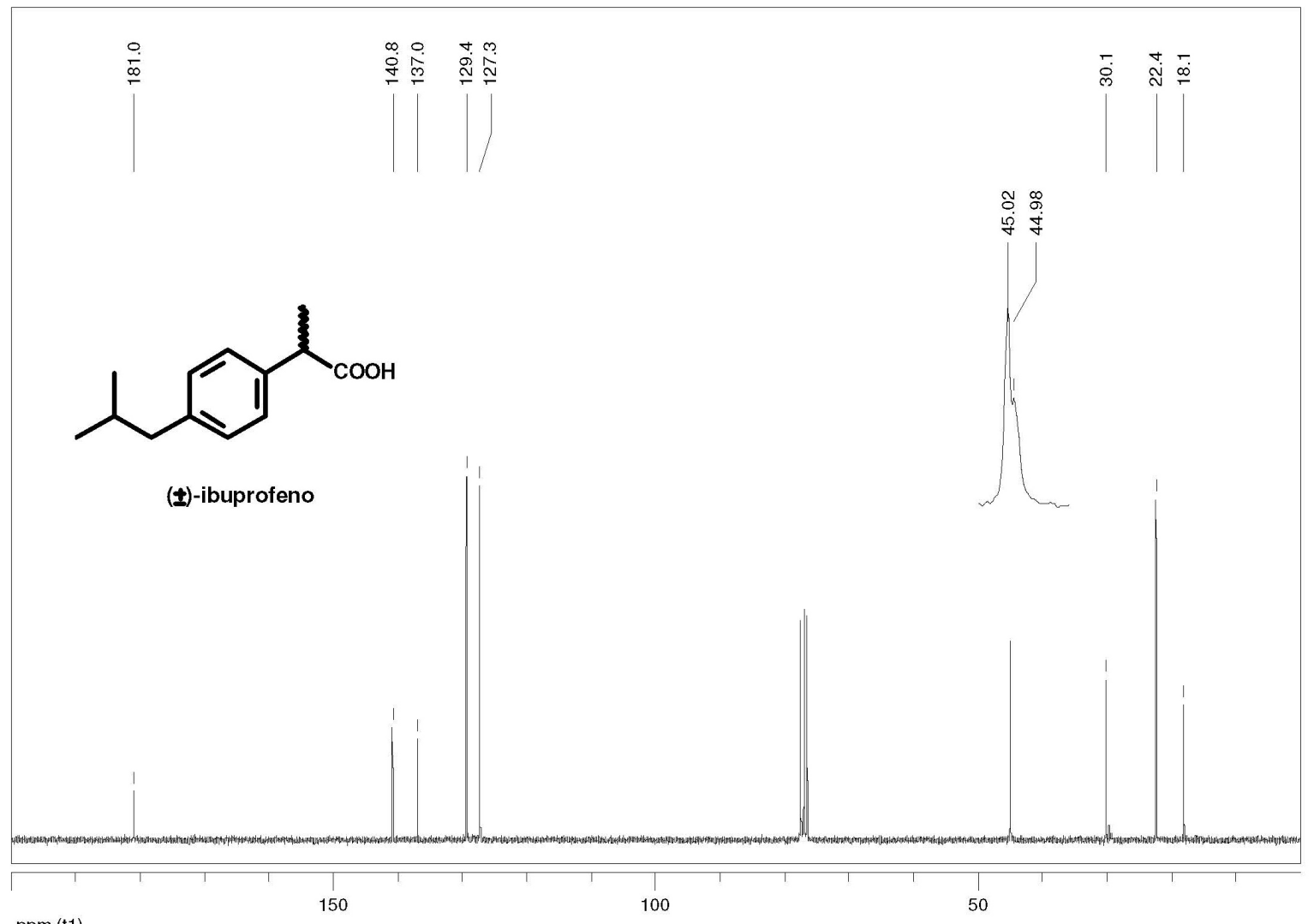

ppm (t1)

Figura $2 \mathrm{~S}$. Espectro de $\mathrm{RMN}$ de ${ }^{13} \mathrm{C}\left(62,5 \mathrm{MHz}, \mathrm{CDCl}_{3}\right)$ do ibuprofeno (1)

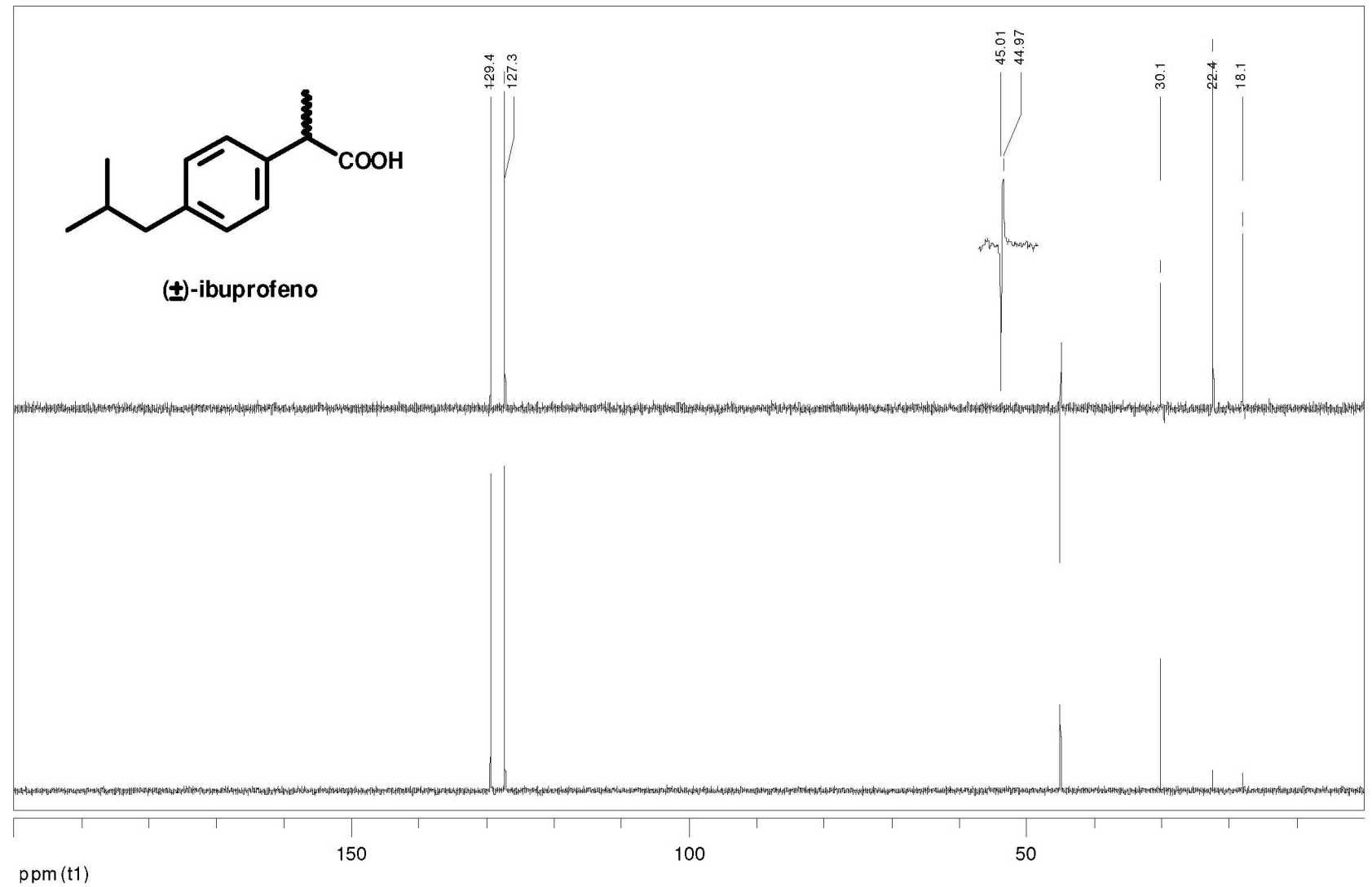

Figura 3S. Espectro de $\mathrm{RMN}^{13} \mathrm{C}-\mathrm{DEPT} 135^{\circ}$ e $90^{\circ}\left(62,5 \mathrm{MHz}, \mathrm{CDCl}_{3}\right)$ do ibuprofeno (1) 


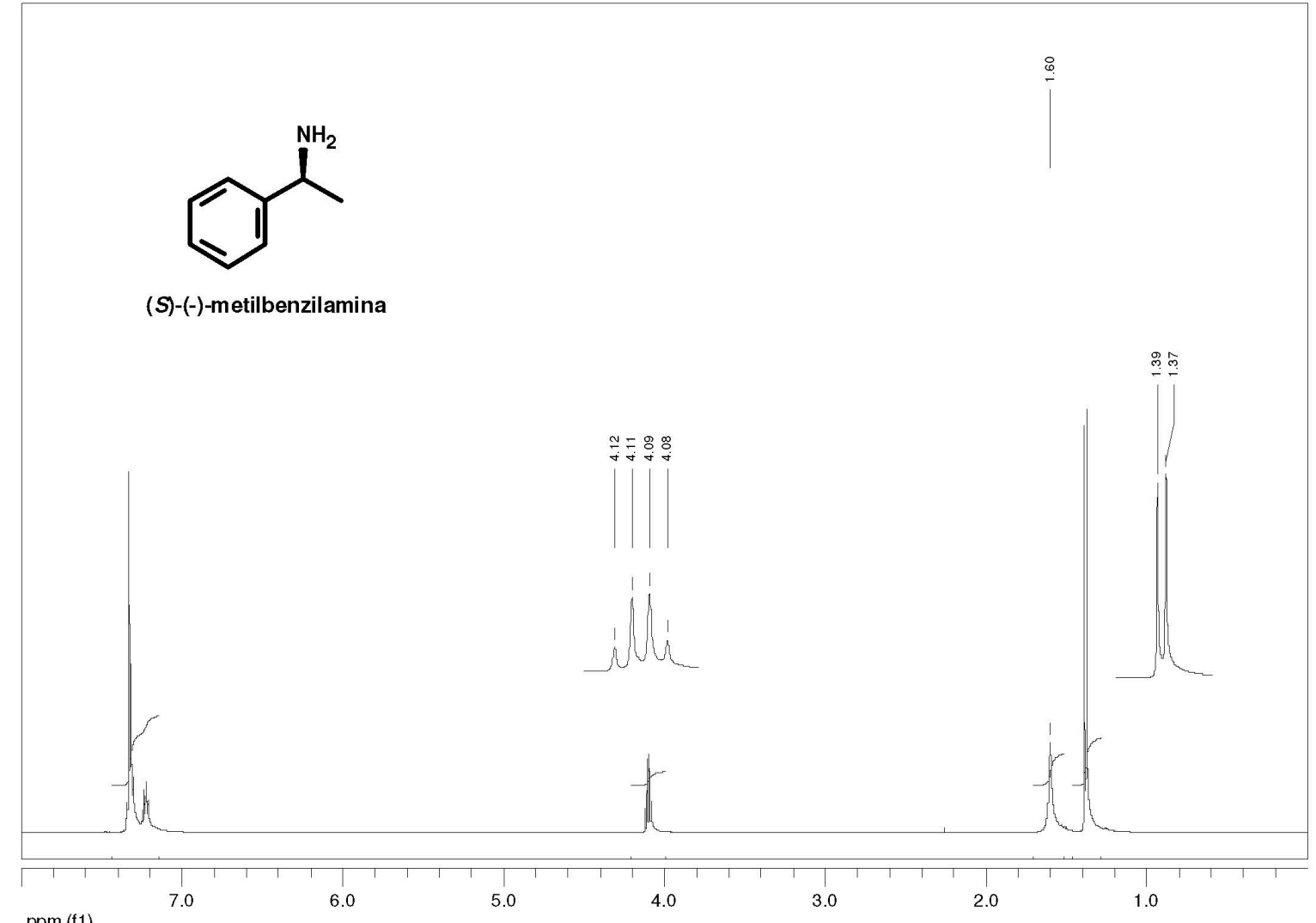

ppm (†1)

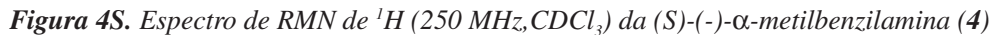

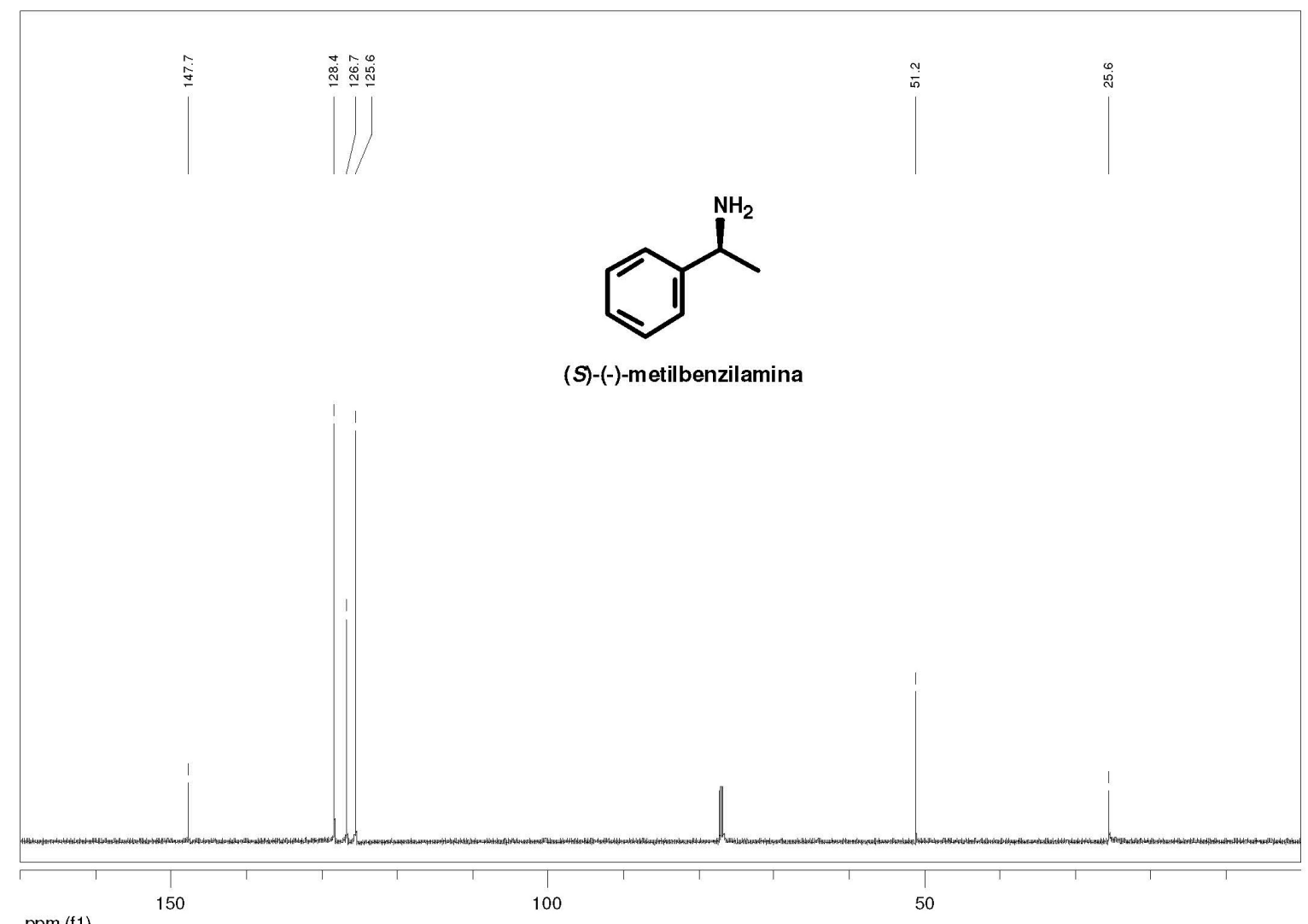

ppm (f1)

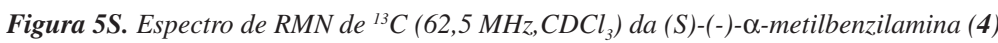


<smiles>CC(C)Cc1ccc([C@@H](C)C(=O)N[C@@H](C)c2ccccc2)cc1</smiles>

$(R, S)$-ibuprofenenamida

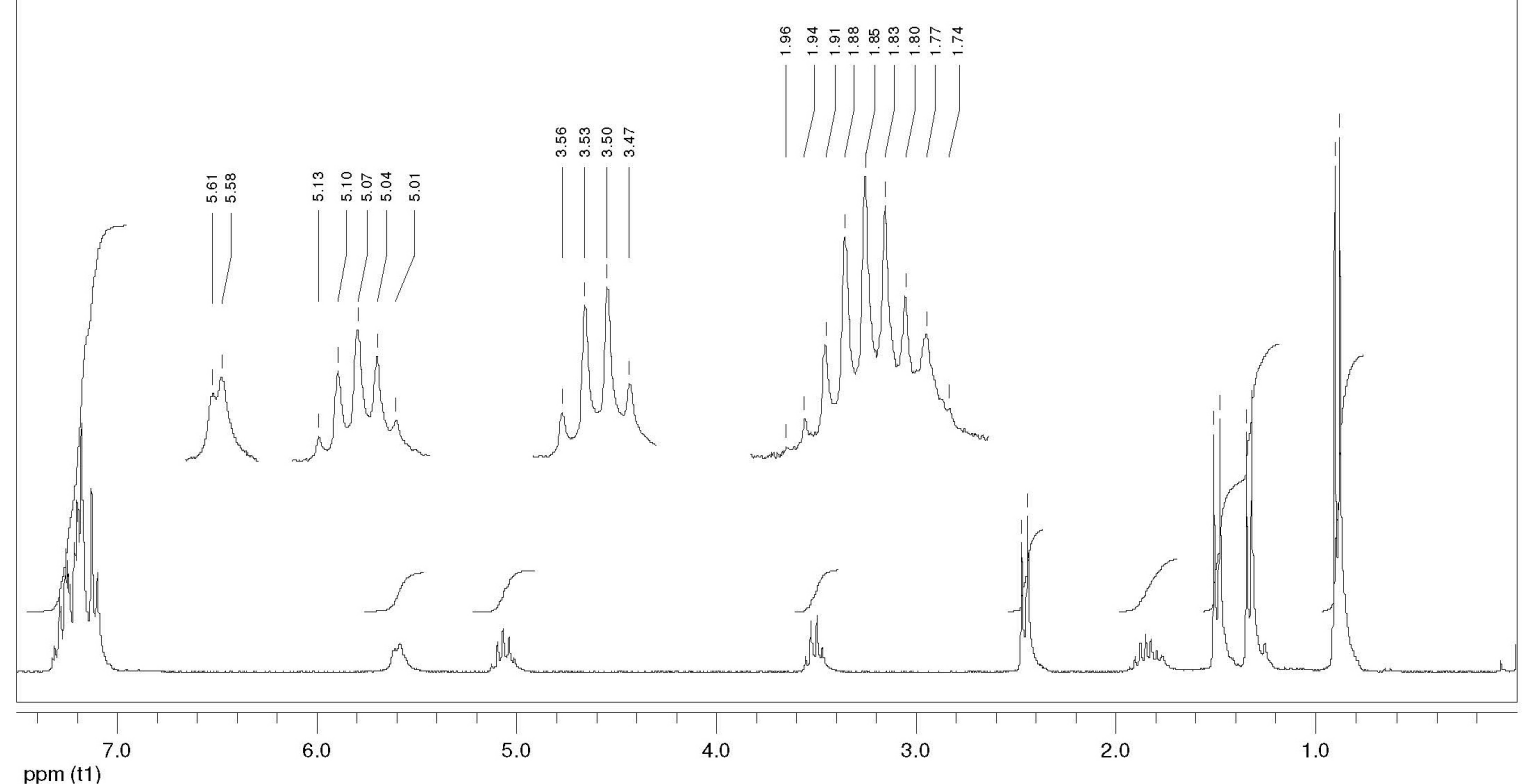

$\mathrm{ppm}(\mathrm{t} 1)$

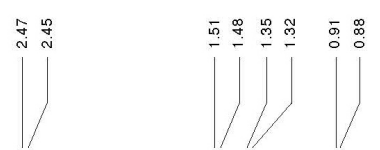

Figura 6S. Espectro de $\mathrm{RMN} \mathrm{de}{ }^{l} \mathrm{H}\left(250 \mathrm{MHz}, \mathrm{CDCl}_{3}\right) d a(R, S)$-ibuprofenamida (6)

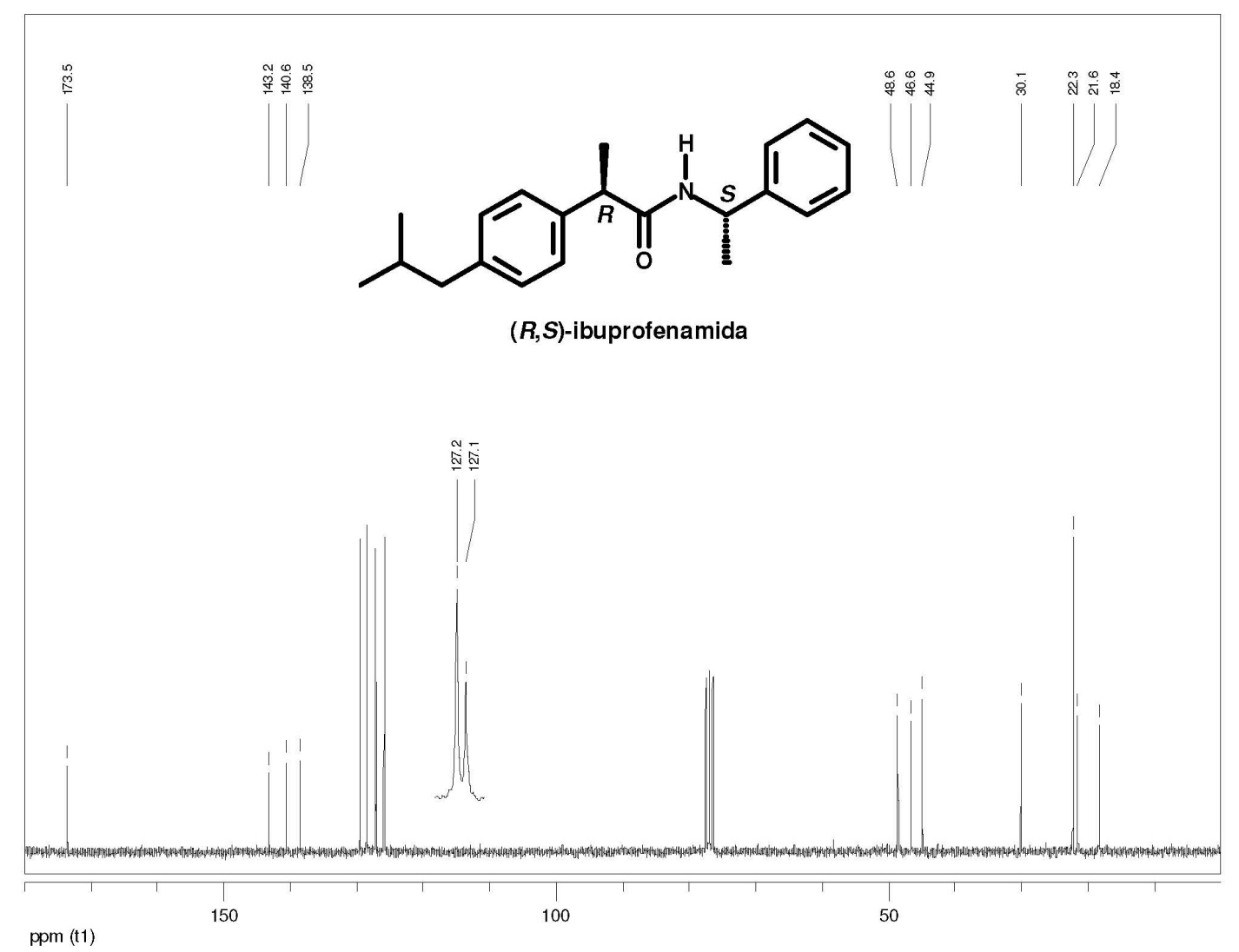

Figura 7S. Espectro de $\mathrm{RMN}$ de ${ }^{13} \mathrm{C}\left(62,5 \mathrm{MHz}, \mathrm{CDCl}_{3}\right)$ da (R,S)-ibuprofenamida (6) 


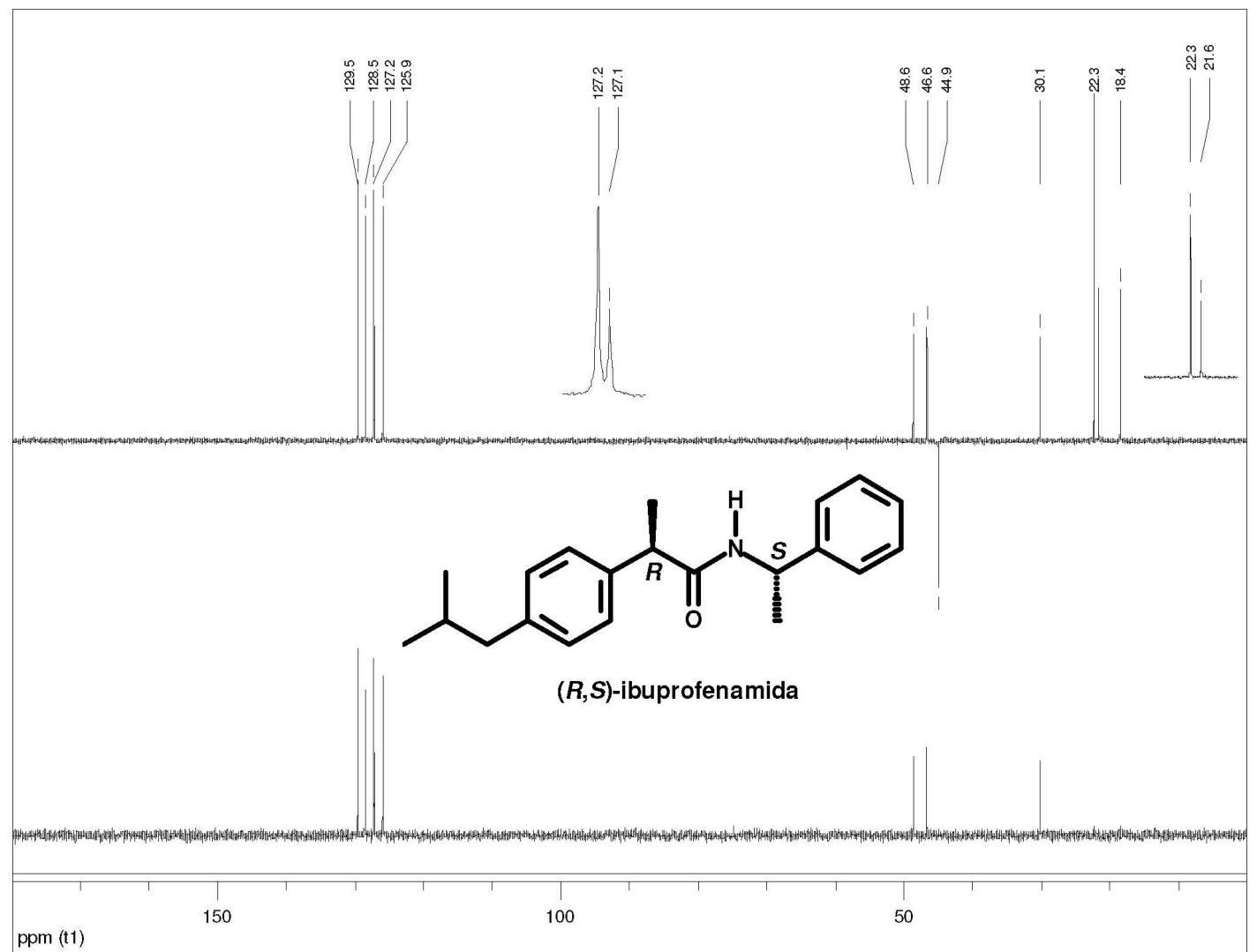

Figura 8S. Espectro de $R M N{ }^{13} \mathrm{C}$ - DEPT $135^{\circ}$ e $90^{\circ}\left(62,5 \mathrm{MHz}, \mathrm{CDCl}_{3}\right)$ da $(R, S)$-ibuprofenamida (6)

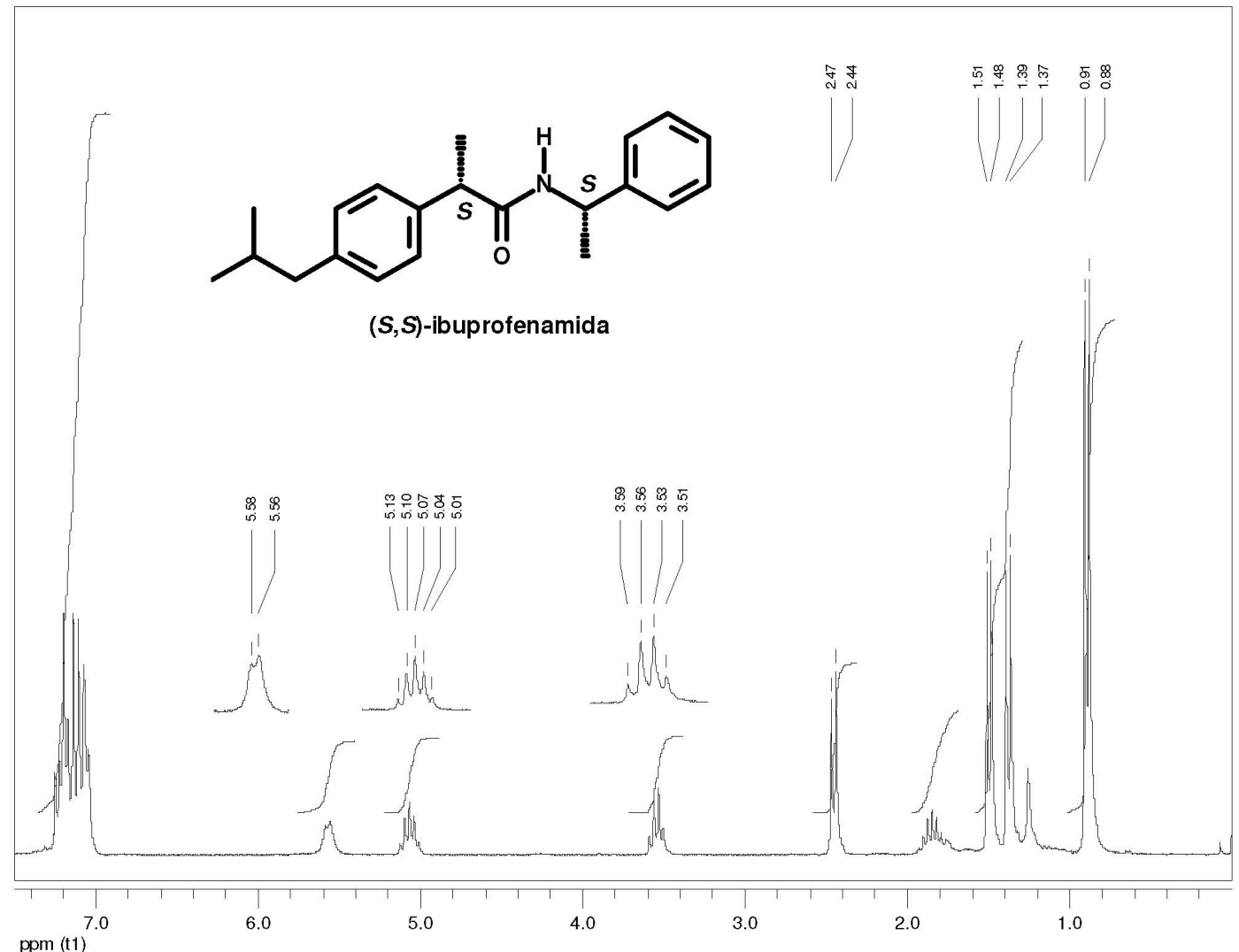

Figura 9S. Espectro de $\mathrm{RMN}$ de ${ }^{l} \mathrm{H}\left(250 \mathrm{MHz}, \mathrm{CDCl}_{3}\right)$ da (S,S)-ibuprofenamida (5) 


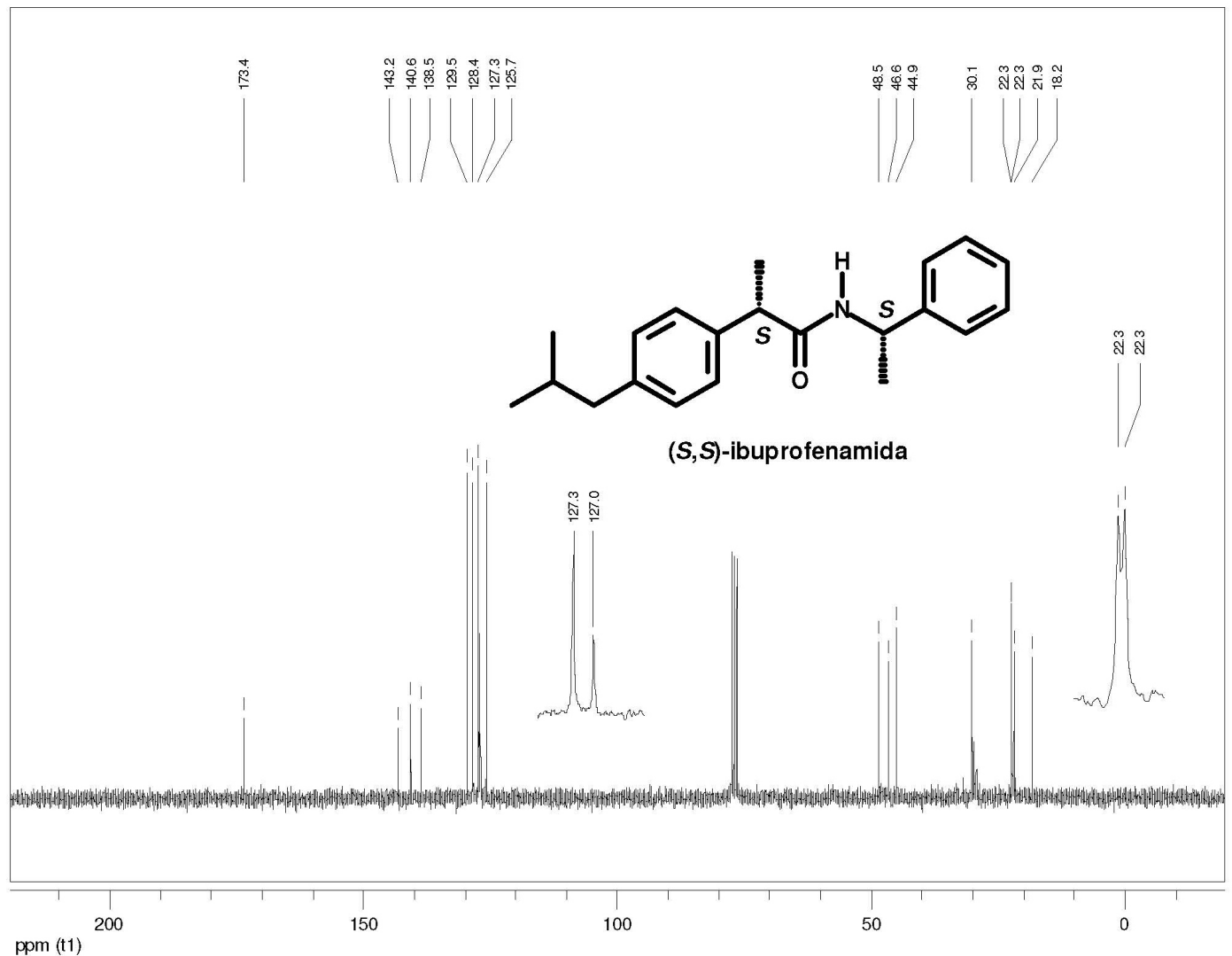

Figura 10S. Espectro de $\mathrm{RMN} \mathrm{de}{ }^{13} \mathrm{C}\left(62,5 \mathrm{MHz}, \mathrm{CDCl}_{3}\right)$ da (S,S)-ibuprofenamida (6)

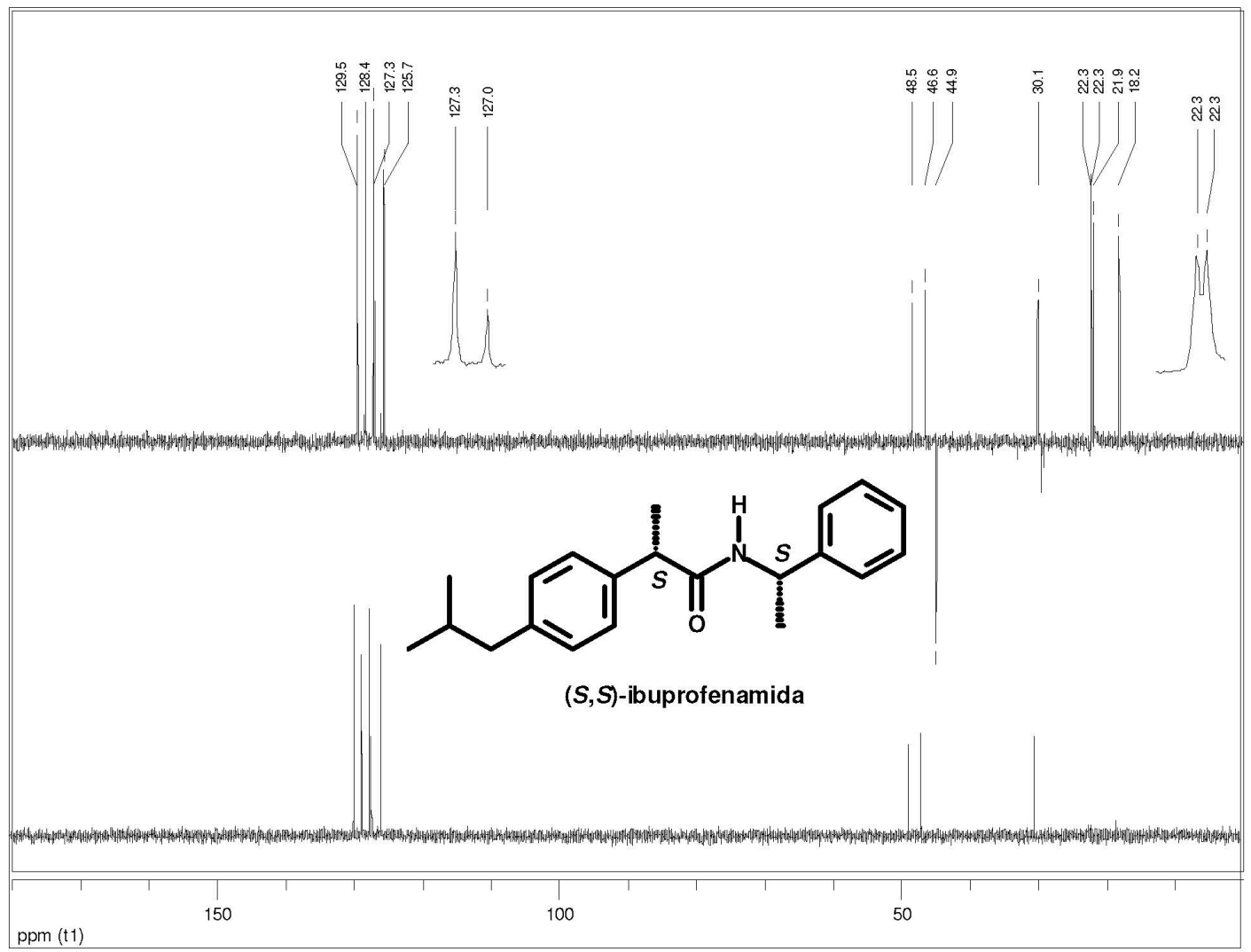

Figura 11S. Espectro de $\mathrm{RMN}^{13} \mathrm{C}-\mathrm{DEPT} 135^{\circ}$ e $90^{\circ}\left(62,5 \mathrm{MHz}, \mathrm{CDCl}_{3}\right)$ da (S,S)-ibuprofenamida (5) 